\title{
N as margens do Estado-nação: as falas da violência na tríplice fronteira amazônica ${ }^{1}$
}

Luiz Fábio S. Paiva

\section{Resumo}

A cidade de Tabatinga, na tríplice fronteira do Brasil com Peru e Colômbia, é constituída por multiplicidades culturais expressas nos diferentes povos, nações e etnias. Em uma complexa região transfronteiriça, brasileiros convivem com populações estrangeiras e povos indígenas de diferentes matizes culturais. Trata-se de uma realidade multifacetada em que pessoas experimentam os mais diversos problemas sociais. Entre eles, as dinâmicas de violências que afetam as maneiras como as pessoas se relacionam entre si e as instituições que integram a vida na fronteira. Neste trabalho, apresento resultados de uma investigação etnográfica sobre como os moradores de Tabatinga falam da violência que afeta sua rotina em um território brasileiro transfronteiriço. Observo como que, ao contar histórias, os interlocutores expõem julgamentos morais e sua visão política sobre o Estado, cidadania e moral na tríplice fronteira amazônica.

Palavras chaves: violência; Estado; fronteira; margens; cultura.

\footnotetext{
${ }^{1}$ Esse trabalho é um dos resultados da pesquisa (In)segurança na Fronteira: uma abordagem sobre como os moradores de Tabatinga falam do perigo e da violência na Tríplice Fronteira Amazônica (Brasil, Colômbia e Peru) e conta com apoio financeiro do Conselho Nacional de Desenvolvimento Científico e Tecnológico (CNPq), através do edital Universal 14/2013, processo 483545/2013-9.

${ }^{2}$ Professor do Departamento de Ciências Sociais e do Programa de Pós-graduação em Sociologia da Universidade Federal do Ceará. Pesquisador do Laboratório de Estudos da Violência da UFC. E-mail: luizfabiocs@yahoo.com.br
} 


\section{On the margins of the nation state: the violence speeches in the Amazonian triple frontier.}

Abstract

The city of Tabatinga, in the Brazil's triple frontier with Peru and Colombia, consists of cultural multiplicities expressed in different peoples, nations and ethnic groups. In a complex cross-border region, Brazilians live with foreign populations and indigenous peoples from different cultural nuances. It is a multifaceted reality in which people experience the most diverse social problems. Among them, the dynamics of violences that affect the ways people relate to each other and institutions that integrate life on the frontier. In this paper, I present results of an ethnographic investigation into how the residents of Tabatinga speak about the violence that affects their routine in a Brazilian cross-border territory. I observe how, by telling stories, the interlocutors expose moral judgments and their political views on the state and citizenship in the Amazonian triple frontier.

Keywords: Violence; State; Frontier; Margins; Culture.

Ao chegar à cidade de Tabatinga, no Amazonas, em uma região de tríplice fronteira do Brasil com Peru e Colômbia, conhecida também como Trapézio Amazônico, o visitante encontra um cenário multicultural, composto por povos de diferentes nações, raças e etnias. Brasileiros de todas as partes do País moram e se relacionam com populações estrangeiras e povos indígenas de diferentes matizes culturais. A cidade dispõe de fronteira seca com a cidade de Letícia, na Colômbia, com a qual forma uma conurbação cujas delimitações dos limites nacionais parecem bastante confusas em determinadas áreas. É possível, por exemplo, encontrar casas que estão nos dois territórios nacionais, entre Brasil e Colômbia. A fronteira com o Peru é fluvial, sendo o centro 
poblado de Santa Rosa uma pequena comunidade do distrito de Yavari, departamento de Loreto. A única forma de contato com Santa Rosa é através de pequenas embarcações que realizam a travessia entre os dois países. Essa realidade transfronteiriça multifacetada tornou-se o campo de uma pesquisa voltada para a compreensão de como os moradores de Tabatinga falam da violência que afeta sua rotina em uma fronteira nacional, entre outras coisas, marcada por redes de influência decorrentes do tráfico internacional de drogas e de políticas de controle social voltadas para a contenção desse tipo de crime.

O objetivo do trabalho é compreender como as pessoas que residem na cidade de Tabatinga "falam da violência" expressando julgamentos morais e visões políticas correspondentes ao sentido subjetivo $^{3}$ que atribuem ao Estado e a cidadania em uma região de fronteira. É oportuno destacar que parto do pressuposto que, como evidencia Albuquerque (2010), o termo fronteira é polissémico e seus usos e significações revelam repertórios culturais variados. Assim, Albuquerque aponta que, ao considerar a fronteira como uma confluência de realidades nacionais distintas, pode-se compreendê-la não apenas como um lugar, mas uma multiplicidade de lugares e experiências. Dessa maneira, exploro informações sobre como compreendi as dinâmicas plurais de pessoas comuns que vivenciam, em seu cotidiano, problemas que envolvem a constituição e as relações entre Estados nacionais.

O conhecimento dos moradores foi a principal fonte de informação qualificada para discutir problemas morais e políticos referentes a um território fronteiriço transpassado por culturas diferenciadas e diferenciadoras das suas relações sociais. Por isso, a perspectiva teórico-metodológica do meu trabalho dialo-

\footnotetext{
${ }^{3}$ Penso aqui na clássica definição de Max Weber (2000) que não considera, necessariamente, o sentido "verdadeiro" ou "correto", mas o sentido visado por agentes que orientam sua percepção do mundo a partir das suas expectativas em relação as pessoas com as quais compartilham situações, espaços e relações sociais.
} 
ga com reflexões presentes nos estudos pós-coloniais que, como sugere Costa (2006), ajudam a pensar as dimensões políticas da cultura, suas formas de negociação e articulação das diferenças e movimentos de construção social de sujeitos descentrados. Essa abordagem ajuda a pensar com surgem, por exemplo, os colombianos e os peruanos nas falas de moradores que usam esses dois sujeitos fronteiriços para falar das violências e conflitos sociais que marcam de maneira muito particular a nação brasileira. Ao seguir esse caminho, considero também as observações de Olivar, Cunha e Rosa (2015) que analisaram as migrações peruanas para o Brasil, na tríplice fronteira, como processos políticos e simbólicos de diferenciação social. Assim, percebo que as "falas da violência" são formas de compreensão dos múltiplos movimentos transfronteiriços que são evidenciados a luz do cotidiano de moradores que vivem na tríplice fronteira.

Outras referências importantes são os estudos de antropologia das margens e do Estado que, conforme Das e Poole (2008), permitem olhares diferenciados para as instituições sociais por possibilitar compreensões do que os grupos sujeitados têm a dizer, não apenas sobre suas vidas, mas sobre a organização política de uma comunidade moral construída na forma de um Estado nacional. 0 trabalho de Das (1999) é uma referência para pensar como os conhecimentos da violência e da dor articulam problemas biopolíticos de governos que, como demonstrou Foucault (1999), atuam sobre a vida das sociedades buscando controlar e normalizar as condutas da população em conformidade com as leis e as formas morais legítimas. Inspirada nessa perspectiva, a investigação percorreu os descaminhos da fronteira e de como as falas da violência explicitam maneiras de subverter controles e tencionar os governos para compreender outros esquemas de legalidade e relacionamentos morais que acontecem nas margens do Estado nação. Assim, do ponto de vista metodológico, as falas da violência foram entradas para reflexões e problematizações a respeito de conflitos sociais que tencionam a definição de Estado e cidadania na tríplice fronteira amazônica. 
Convém esclarecer que não foi minha intenção utilizar um conceito de violência que abrangesse determinado perfil de problemas sociais. Sobre o conceito, os cientistas sociais parecem concordar que ele é polissêmico e sua percepção envolve os limites éticos e morais historicamente construídos e correspondentes às formas culturais de determinada sociedade (ZALUAR, 2004). Neste trabalho, absorve-se a ideia de polissemia da violência, explorando a pluralidade semântica do conceito ${ }^{4}$. Assim, as interpretações da violência na fronteira é uma porta de entrada para saber como é a vida na cidade de Tabatinga, considerando os fluxos entre os povos que constituem o Trapézio Amazônico. Observa-se como a violência empresta sentidos que são, discursivamente, retratados por pessoas que começaram a falar sobre o assunto, mas exploraram o mundo social em que vivem de múltiplas maneiras. Ao falar da violência elas falam de coisas da vida, da sua cidadania, das suas expectativas em relação aos governos, do que acham de peruanos, colombianos e indígenas, além de uma série de outros problemas que já compõem certo excesso de bagagem da pesquisa de campo. Manter o foco não foi uma preocupação porque esse investimento de pesquisa desejava que os moradores nos mostrassem os caminhos da fronteira e os problemas que eles julgam importante para entender um território de "interesse nacional". As conversas e entrevistas ${ }^{5}$ que subsidiam essa reflexão começaram basicamente com a seguinte pergunta: “como é a vida aqui em Tabatinga?” Para alguns esclarecimentos sobre o trabalho de campo, farei algumas considerações metodológicas gerais para que o leitor possa se situar no universo dessa pesquisa.

\footnotetext{
${ }^{4}$ Sobre as ambiguidades referentes a significação de atos e representações da violência ver FREITAS, Geovani Jacó de. Ecos da violência: narrativas e relações de poder no Nordeste canavieiro. Rio de janeiro: Relume Dumará, 2003.

${ }^{5}$ As pessoas entrevistadas não são identificadas no texto em virtude de compromisso assumido durante o processo de pesquisa. Utilizo apenas algumas qualificações gerais para situar o contexto da fala.
} 


\section{Considerações metodológicas sobre o trabalho de pesquisa na tríplice fronteira amazônica}

É oportuno ressaltar que a pesquisa que subsidia esse trabalho é resultado de um processo de investigação construído em torno de parcerias entre instituições de ensino e pesquisa. Por isso, é fundamental esclarecer que o trabalho que apresento aqui é devedor de outros trabalhos, entre eles, o do Observatório da Violência de Gênero do Amazonas, coordenado pela professora Flávia Melo da Cunha do Instituto de Natureza e Cultura da Sede de Benjamin Constant da Universidade Federal do Amazonas ${ }^{6}$. Foi através do Observatório que conheci a cidade de Tabatinga no ano de 2012. Ao chegar, em Tabatinga, encontrei uma cidade no meio da Floresta Amazônica, com forte presença militar e uma diversidade cultural observável pelas diferenças expressadas nas circulações de indígenas, turistas estrangeiros, brasileiros de outras regiões, colombianos e peruanos, entre outros. Então, logo nas primeiras andanças e conversações, percebi que o território de Tabatinga é um espaço social de confluências entre povos que compõem uma comunidade política singular no contexto nacional, extremamente afetada pela ideia de ser uma Cidade constituída no interior da "maior região produtora de cocaína do mundo".

Em 2014, após um período de reflexão sobre a realidade da tríplice fronteira, construí juntamente com Lindomar Albuquerque (UNIFESP), Flávia Cunha (UFAM), Camila Holanda (FAMETRO), Igor Monteiro (UFC) e Maurício Russo (UFC) um projeto de pes-

\footnotetext{
${ }^{6}$ O Observatório da Violência de Gênero no Amazonas foi criado em 2012 e atua em três unidades acadêmicas da Universidade Federal do Amazonas: Instituto de Natureza e Cultura (Benjamin Constant), Instituto de Ciências Sociais, Educação e Zootecnia (Parintins) e Instituto de Ciências Exatas (Manaus). Entre outros trabalhos, o Observatório tem realizado mapeamentos sobre a violência contra a mulher no alto Solimões e atuado no âmbito do projeto que subsidia esse trabalho. Cf. OBSERVATÓRIO DA VIOLÊNCIA DE GÊNERO NO AMAZONAS. Mapa da violência contra mulheres na mesorregião amazônica do Alto Solimões-AM. Benjamin Constant, AM: Universidade Federal do Amazonas, 2013. Disponível em http://radios.ebc.com.br/sites/_radios/files/mapa_da_violencia_contra_mulheres_no_alto_solimoes.pdf. Acesso em 21/05/2015.
} 
quisa submetido ao CNPq com intuito de investigar como a violência afeta a vida dos moradores, trabalhando seus relatos sobre a vida na tríplice fronteira. A intenção inicial foi saber como os moradores falam de situações de violência que permeiam o dia a dia em um território reconhecido como parte da maior floresta tropical do mundo e, também, situado na região de maior produção de cocaína do mundo. A princípio, essas duas ideias pareciam aos pesquisadores envolvidos no projeto extremamente abrangentes e curiosas, despertando o desejo coletivo em saber como pessoas comuns conviviam com imagens e práticas que tornavam a tríplice fronteira amazônica um lugar peculiar para pensar, por exemplo, situações de violência. Saber o que as pessoas têm a falar sobre a violência em Tabatinga foi o interesse que mobilizou a iniciativa e permitiu interpretar a fronteira não em sua totalidade, mas a partir de um ponto de partida que foi desenvolvido ao longo das incursões em campo e diálogos com os mais diversos sujeitos que passaram a compor uma complexa rede de interlocutores.

Falar com os moradores sobre os problemas da violência em Tabatinga não foi uma meta para atender a um fim, mas uma porta de entrada para compreender uma realidade dinâmica entre pessoas de países, cidadanias e culturas diferenciadas. Para fins dessa abordagem, realizei junto com outros pesquisadores incursões etnográficas à cidade com o intuito de conversar e interagir com os moradores de Tabatinga sobre como eles veem o problema da violência na fronteira e quais as implicações dele em suas vidas. Ao todo, foram três períodos de pesquisa, no ano de 2014, cada qual com permanência de 15 dias e mais um, em 2015, com permanência de 10 dias. Nestes períodos, as conversas e entrevistas foram realizadas com pessoas que moram, trabalham ou frequentam a cidade de Tabantinga (brasileiros, indígenas, colombianos e peruanos). Muito menos do que um perfil desejado, foi um perfil construído no decorrer de um trabalho de campo sujeito, entre outras coisas, a séries de encontros não previstos e andanças não planejadas pelas três cidades que compõem a tríplice fronteira. Buscou-se aprender com os morado- 
res dessa região como eles a interpretavam e a analisavam do seu ponto de vista político ao considerar, sobretudo, questões relacionadas à violência na tríplice fronteira amazônica.

No decorrer do trabalho de campo, outros sujeitos se juntaram ao esforço da equipe inicial como colaboradores e interlocutores significativos de uma pesquisa-processo que é resultado de muitos compartilhamentos. No decorrer desse trabalho, encontrei pesquisadores que atuam em Tabatinga e pude aprender com eles suas leituras e reflexões sobre uma região repleta de coisas "incríveis para se pesquisar". Sem dúvida, a possibilidade de fazer campo, em 2015, com José Miguel Nieto Olivar foi de uma riqueza inestimável, pois seus conhecimentos da tríplice fronteira amazônica me proporcionaram acesso a muitas informações privilegiadas sobre o campo ${ }^{7}$. Foi imprescindível também o acolhimento de pesquisadores da Universidade Federal do Amazonas e da Universidade Estadual do Amazonas. Flávia Melo da Cunha nos ajudou a compreender como outras violências, entre elas a doméstica, afetam muito mais a comunidade local do que a do tráfico de drogas ${ }^{8}$. Rodrigo Oliveira Braga Reis colaborou com esclarecimentos sobre conflitos que envolvem povos indígenas que atuam na região, no auxiliando também em compreender um pouco mais sobre conjuntura sociopolítica da tríplice fronteira ${ }^{9}$. Pedro Henrique Coelho Rapozo me propor-

${ }^{7}$ José Miguel Nieto Olivar é colombiano e pesquisador do Núcleo de Estudos de Gênero PAGU. Atualmente coordena o projeto de pesquisa "Gênero em territórios de fronteira e transfronteiriços na Amazônia brasileira" cujo objetivo é a análise das articulações entre gênero e fronteiras na Amazônia brasileira, tendo como campo as cidades de Tabatinga, São Gabriel da Cachoeira (AM) e Altamira (PA).

8 Flávia Melo da cunha é professora da UFAM e coordenadora do Observatório da Violência de Gênero no Amazonas. Seu trabalho envolve dezenas de estudantes da região e tem contribuído para dar visibilidade a um problema vivido em silêncio por mulheres vítimas de violência na região do Alto Solimões.

${ }^{9}$ Rodrigo Oliveira Braga Reis é professor da UFAM e coordenador do Núcleo de Extensão e Pesquisa para o Desenvolvimento Territorial do Alto Solimões (CNPq/MDA/SPM). As suas reflexões tem se dedicado a compreensão geopolítica e dinâmicas de povos indígenas que vivem na região do Alto Solimões. 
cionou conhecimentos sobre múltiplos conflitos que acontecem no Alto Solimões, revelando outras violências relacionadas a problemas socioambientais que afetam as populações tradicionais e colocam desafios importantes para constituição do Estado de direito na Amazônia brasileira ${ }^{10}$. Reginaldo Conceição da Silva nos mostrou um pouco da cultura afro-religiosa presente na cidade de Tabatinga, abrindo as portas para outros cenários relacionados à Umbanda na tríplice fronteira amazônica ${ }^{11}$. Por fim, não é possível deixar de ressaltar o papel importantíssimo do antropólogo Enio Gilberto Haiden Mendonça que me guiou pelos muitos lugares de uma ainda desconhecida Tabatinga durante as primeiras incursões em campo, me ensinando sobre as dinâmicas que compõem uma cidade fronteiriça dotada de problemas muito peculiares ${ }^{12}$. Esses pesquisadores compõem uma rede importante em um processo etnográfico colaborativo no qual diversas investigações dialogam em um regime de trocas de conhecimento sobre a tríplice fronteira.

Nesse processo colaborativo me senti, inúmeras vezes, agraciado pela possibilidade de não apenas trabalhar com os relatos, mas também com as múltiplas reflexões de pesquisadores que tem a tríplice fronteira e a região do Alto Solimões como seu campo de pesquisa. Isso me pareceu bastante frutífero e possibilitou, em diversos momentos, preencher lacunas decorrentes de curtos

${ }^{10}$ Pedro Henrique Coelho Rapozo é professor da Universidade Estadual do Amazonas (UEA) e coordena o projeto "Mapeamento participativo e Identificação de Conflitos Socioambientais na Tríplice fronteira Brasil/Colômbia/Peru: Elementos para políticas públicas na resolução e gestão dos recursos naturais de uso comum" cujo objetivo é a identificação ode situações de conflito na mesorregião do Alto Solimões resultantes do uso e apropriação dos recursos naturais por grupos não-indígenas localizados nos municípios da tríplice fronteira.

${ }^{11}$ Reginaldo Conceição da Silva é professor da UEA, integrante da equipe do projeto "Mapeamento participativo e Identificação de Conflitos Socioambientais na Tríplice fronteira Brasil/Colômbia/Peru: Elementos para políticas públicas na resolução e gestão dos recursos naturais de uso comum" e realiza também pesquisas sobre resistência cultural afro-religiosos da cidade de Tabatinga.

12 Enio Gilberto Haiden Mendonça é graduado em antropologia na UFAM e realizou pesquisa sobre as dinâmicas locais do mercado ilegal de drogas na tríplice fronteira. 
períodos de trabalho frente às demandas da tríplice fronteira amazônica. Em outros momentos, as contingências de um trabalho em equipe me permitiu o prazeroso exercício de aprender fazendo, ouvindo e exercitando junto com outros pesquisadores descobertas de um campo repleto de dificuldades. Entre elas, o fato de falar a respeito de situações de violência com pessoas que nem sempre se encontram a vontade para tratar de um assunto relativamente delicado ${ }^{13}$ na cidade de Tabatinga. Em determinados momentos, durante o trabalho de campo, me senti muito incomodado com algumas situações que trato como delicadas para não falar perigosas.

Ao longo do processo de investigação, estive em galleras $^{14}$, cassinos, ocupações, bares, boates, cabarés, rios, quebradas, ruas, comunidades entre outros lugares. Sobre alguns desses lugares pesava a acusação de serem "perigosos" e frequentados por pessoas envolvidas com o crime na região. Na maior parte desses lugares contei com a parceria de José Lindomar Coelho Albuquerque $^{15}$, entre outros colegas que facilitaram nossas entradas em muitos dos lugares referidos. A maior parte da nossa circulação na tríplice fronteira foi tranquila, com entradas e saídas sem maiores problemas dos mais diversos lugares visitados. Algumas ocorrências, no entanto, marcaram nossa percepção desses lugares. Certo dia, por exemplo, na boate Scandalos, principal casa de show de Tabatinga, um amigo da cidade nos apresentou a conhecidos seus como "policiais federais". Mesmo em tom de brincadeira, a situação me irritou bastante e passei aquela noite inteira incomodado. Em outra ocasião, estávamos na cidade de

\footnotetext{
${ }^{13}$ Sobre a pesquisa a respeito de temas delicados ver BARREIRA, César. Cotidiano despedaçado: cenas de uma violência difusa. Coleção Conflitos Sociais e Práticas Políticas. Campinas: Pontes, 2008.

${ }^{14}$ Locais em que se realizam brigas de galo na Colômbia.

${ }^{15}$ José Lindomar Coelho Albuquerque é professor da Universidade Federal de São Paulo (UNIFESP) e realiza pesquisas também na tríplice fronteira Argentina, Brasil e Paraguai. Coordena o Núcleo de Estudos Fronteiriços da UNIFESP e tem uma significativa produção sobre as dinâmicas que permeiam as fronteiras como problema das Ciências Sociais.
} 
Letícia, em plena segunda-feira, passeando por cassinos, bares e lugares para jogar sinuca. No dia anterior, tínhamos estado em uma gallera e muitas pessoas que tínhamos encontrado lá voltávamos a ver em nossa andança de segunda. A possibilidade de estar sendo "observado, observando" criou a preocupação de nossa presença causar "incômodos" em pessoas que realizam atividades ilegais e, evidentemente, controlam seus espaços de circulação com cuidados específicos.

Obviamente campo é um espaço dinâmico e imprevisível. Entre as questões que provocaram inquietações esteve o encontro de uma gallera a um metro da fronteira brasileira. Além de curiosa, a situação me pareceu emblemática das singularidades desse campo. Chegamos ao local da referida gallera nas primeiras horas da manhã. Ficava ao lado da comunidade brasileira conhecida como Vila Guadalupe, localizada na fronteira entre Brasil/ Tabatinga e Colômbia/Letícia, a beira do Rio Solimões. Convém ressaltar que as brigas de galo são proibidas no Brasil, mas legais na Colômbia e no Peru ${ }^{16}$. 0 fato de a gallera estar próxima à linha de fronteira, em uma área aparentemente inóspita do lado colombiano, nos levou a suspeitar de que ali os brasileiros haviam construído um lugar para suas brigas de galo. Então, enquanto faziam um registro fotográfico, meus colegas de pesquisa perguntaram a moradores sobre o local, "o que se fazia ali", "quando era possível ver as brigas de galo", entre outras perguntas que me provocaram grande incômodo. Além de presenças estranhas, as nossas perguntas perturbavam um cotidiano desconhecido que não me parecia tão fácil de acessar quanto aos meus colegas. A coragem de meus colegas, no entanto, foi fundamental para aquisição de muitas informações que eu não teria acessado sozinho em razão das minhas disposições em campo. Assim, nossas diferenças se tornaram estruturantes da possibilidade de discu-

${ }^{16}$ Cf. ALBUQUERQUE, José Lindomar; PAIVA, Luiz Fábio Silva. Entre nações e legislações: algumas práticas de "legalidade" e "ilegalidade" na tríplice fronteira amazônica (Brasil, Colômbia, Peru). Revista Ambivalências, v. 3, n. 5, p. 115-148, 2015. 
tir nossas posições em campo e as maneiras de acessar lugares e pessoas na fronteira.

Outra questão importante foi como falar sobre as situações de violência na tríplice fronteira. Como observado por Das (2008), falar da violência é uma experiência que revela as dinâmicas da cultura, expressando as maneiras pelas quais o mundo social faz sentido ou ganha sentido. Para ela, mesmo o silêncio em torno de uma experiência traumática é um dado importante para pensar os sentidos que marcam a história de pessoas e grupos. Caldeira (2003), em suas investigações sobre a cidade de São Paulo, observou também como a "fala do crime" oferece significado sobre uma experiência que desconstrói o cotidiano de pessoas que, entre outras coisas, classificam o mundo a partir de suas percepções como vítimas de um acontecimento que perturba suas vidas. Considero falar da violência e do crime formas de relatar acontecimentos que marcam a vida e permeiam o dia a dia, independentemente de as falas expressarem ou não acontecimentos verdadeiros. Em Tabatinga, encontrei interlocutores que me narraram situações de violência que não os afetaram diretamente, mas constituem sua narrativa sobre a tríplice fronteira. As falas da violência se mostraram elementos constituintes de lugares, sujeitos e acontecimentos estruturantes do que é a tríplice fronteira e os diversos personagens que a compõem. Observo nessas falas diferentes repertórios culturais que estruturam as práticas e o imaginário dos moradores sobre a tríplice fronteira, seus trânsitos e relações. Trabalho as falas dos meus interlocutores como portadoras de conteúdos de sentido capazes de ser pensados sociologicamente, ao exporem as experiências distintas e compartilhadas de pessoas que vivem nas margens do Estado nação brasileiro.

Em suma, preparei essa reflexão sobre as falas da violência em Tabatinga, tendo em vista três eixos que me parecem compor um cenário preliminar e bastante conhecido dos meus interlocutores, em suas linhas gerais. No primeiro momento, me dedico 
a pensar sobre a construção midiática de um discurso abrangente sobre a violência em Tabatinga, explorando as inúmeras ocorrências jornalísticas que apresentam o lugar em reportagens sobre a segurança nacional e o tráfico internacional de drogas. A seguir, exploro a dinâmica interna da cidade, sobretudo, em sua relação com o narcotráfico como elemento estruturante de relações sociais na tríplice fronteira amazônica. Por fim, reflito sobre problemas identificados pelos moradores como preocupantes para o seu dia a dia na Cidade e que dialogam com o discurso mais amplo a respeito da violência na região.

\section{U ma "cidade perigosa" no meio da maior floresta e da maior região produtora de cocaína do mundo}

É possível conhecer Tabatinga pelos telejornais brasileiros. 0 problema desse conhecimento via mídia é ter uma visão peculiar de um lugar que, em geral, só aprece para o resto do País como cenário de problemas de segurança nacional ou do tráfico internacional de drogas. Os discursos midiáticos a respeito da violência na tríplice fronteira amazônica repercutem uma ideia de que o território é repleto de perigos que ameaçam o País de diferentes formas. Entre os perigos ressaltados pela imprensa nacional, estão ameaças à soberania nacional em decorrência de ataques de guerrilhas que atuam em território colombiano, como no caso da emboscada ao exercito brasileiro, nas margens do Rio Traíra. Existem símbolos e referências a essa experiência que são possíveis de ser visualizadas na chegada ao aeroporto da Cidade, localizado na base do Comando de Fronteira do Solimões/8ํㅡ Batalhão de Infantaria de Selva (CFSol/8o BIS).

0 ataque ao exercito brasileiro no Rio Traíra pode ser acompanhado em um vídeo no Youtube ${ }^{17}$ que começa com o seguinte

${ }^{17} \mathrm{O}$ vídeo referido mostra uma reportagem especial da Rede Globo de Televisão e está disponível em https://www.youtube.com/watch?v=2YN2eDwfVfk. Acesso em 06/09/2015. 
anúncio: "a atenção do mundo estava voltada para o $31^{\circ}$ dia da operação Tempestade no Deserto na Guerra do Golfo contra o Iraque, enquanto isso, no extremo Oeste da Amazônia Brasileira às margens do Rio Traíra.... A partir daí, a matéria apresenta soldados do exercito brasileiro que chegam a Tabatinga após sofrerem uma emboscada, em um posto avançado do exército, nas margens do Rio Traíra. 0 ataque, segundo as forças armadas, foi resultado de uma ação das Forças Armadas Revolucionárias da Colômbia (FARC), mais especificamente de um grupo de 40 guerrilheiros autodenominados Comando Simon Bolivar. A matéria de 1991 da Rede Globo de Televisão apresenta um jovem Caco Barcellos ${ }^{18}$ embrenhado na floresta, na área de fronteira do Brasil com a Colômbia. Ele investigava a emboscada e a suspeita de a mesma ter sido protagonizada por garimpeiros que atuavam na região rica em ouro.

As suspeitas em torno da presença e da atuação das FARC no trapézio amazônico são elementos importantes na configuração do território e estruturantes de múltiplas iniciativas das forças armadas de Brasil, Colômbia e Peru. Desde as primeiras incursões escutei narrativas sobre os perigos das FARC, inclusive, sobre a existência de uma placa, nos "quilômetros"19 em Letícia, que conteria um aviso para as pessoas não seguirem viagem devido à presença de guerrilheiros na região. Segundo Ramirez (2009), o temor em relação ao conflito armado colombiano atuou de maneira muito específica na maneira como o exercito brasileiro definiu sua própria identidade após o final da Ditadura e

\footnotetext{
${ }^{18}$ Jornalista brasileiro das Organizações Globo, vencedor do Prêmio Jabuti em duas ocasiões, com seus livros "Rota 66: a história da polícia que mata" e "Abusado: o dono do morro Dona Marta".

19 "Os quilômetros", em Letícia, é como os moradores se referem a uma estrada que, em tese, começou a ser construída para escoar cocaína para a cidade Tarapacá. Dos 170 km previstos apenas os primeiros $23 \mathrm{~km}$ foram construídos e nas suas margens existem balneários que atraem turistas e moradores. Ver verbete Letícia (Colômbia) na Wikipédia. Disponível em https://pt.wikipedia.org/wiki/Leticia_(Col\%C3\%B4mbia). Acesso em 25/09/2015.
} 
estabeleceu seu papel na região de fronteira com o País. Além do conflito no Traíra, Ramirez destaca a tentativa de invasão da fronteira por guerrilheiros, em 1998, e o pouso de aviões militares colombianos na pista brasileira de Querari, em resposta à ataque da FARC a uma base militar em Mitu. Contudo, além de acontecimentos esporádicos, a presença das FARC na tríplice fronteira funciona como um elemento narrativo que permeia a imaginação de moradores que, por exemplo, acusam motoristas de Tuc-tuc's ${ }^{20}$ de serem pessoas ligadas as guerrilhas colombianas. A existência de guerrilheiros aparece, em determinados momentos, muito mais como uma acusação espontânea do que como fato concreto, mas é preciso melhores informações para poder afirmar o alcance dessa narrativa na composição do imaginário transfronteiriço.

Além de um enclave estratégico em programas de segurança nacional, Tabatinga é geralmente retratada pela imprensa brasileira como uma cidade perigosa, situada no Trapézio Amazônico, "a maior região produtora de cocaína do mundo". Isso tornou tabatinga palco de matérias sobre violência e tráfico internacional de drogas nas fronteiras brasileiras. Ao lado de Corumbá, Brasiléia e Foz do Iguaçu, Tabatinga é retratada, em geral, com uma das principais portas de entrada de drogas do país e local privilegiado para repórteres que "adoram ir onde está a notícia". É possível encontrar reportagens sobre o mercado ilegal da droga em grandes canais de TV como Rede Globo de Televisão, Rede Record e SBT. Muitas matérias são "especiais”, com repórteres que vão até a fronteira e ressaltam "os caminhos da droga no Brasil”. É importante destacar também que o objeto privilegiado das matérias a respeito do tráfico na tríplice fronteira amazônica é a cocaína. As reportagens também não deixam de retratar os assassinatos associados ao tráfico na região. Em linhas gerais,

${ }^{20}$ O Tuc-tuc é uma espécie de triciclo motorizado utilizado, em Letícia e Santa Rosa, para o transporte de passageiros. Embora possam transportar passageiros de Letícia para o Brasil, os motoristas de Tuc-tuc são proibidos de recolher passageiros em Tabatinga. 
as matérias abordam denúncias de pessoas nas sombras, retratam análises de especialistas e policiais que atuam na região, exploram como a droga circula pelo rio, revelam como laboratórios foram descobertos e desmantelados e, sempre que possível, mostram imagens dos corpos de pessoas assassinadas. Entre os telejornais que abordaram a questão está o Jornal Nacional da Rede Globo de Televisão. 0 mesmo dedicou mais de 4 minutos do seu tempo a uma cobertura sobre o tráfico e a violência em Tabatinga.

O Jornal Nacional está exibindo essa semana uma serie de reportagens sobre as Fronteiras da Amazônia. Na última etapa dessa viagem de 15.000 quilômetros, Luiz Filião e Cristina Serra encontraram uma cidade sitiada pela violência do narcotráfico. (Fátima Bernardes) ${ }^{21}$.

A fala de Fátima Bernrdes abre a notícia sobre a cidade de Tabatinga, ou seja, "a cidade sitiada pela violência do narcotráfico". Após a fala da ancora do Jornal Nacional, a matéria se desdobra mostrando um locutor que faz referência à diversidade cultural entre brasileiros, colombianos e peruanos. Em seguida, a repórter Cristina Serra dá boas vindas "a capital brasileira das motocicletas", tratando como "pitorescas" certas ilegalidades cotidianas como o aluguel de capacetes por brasileiros para atravessar a fronteira entre Tabatinga e Letícia ${ }^{22}$, assim como a compra de motos na cidade colombiana sem pagamento de impostos a receita federal brasileira. Após essa introdução, a repórter ressalta que a fronteira entre Tabatinga e Letícia é a mais fácil de atravessar e também "a mais explosiva e perigosa" das visitadas durante a reportagem "Fronteiras da Amazônia". A matéria ganha

${ }^{21} \mathrm{O}$ vídeo foi publicado em 10 de fevereiro de 2013 no YouTube. Disponível em https:// www.youtube.com/watch?v=UIqYs1jEDUA. Acesso em 29/08/2015.

${ }^{22}$ Como a fiscalização do uso de capacetes por motociclistas em Letícia era mais rigorosa do que em Tabatinga, brasileiros que trafegavam entre as duas fronteiras alugavam um capacete para circular de moto em território colombiano. Cf. Albuquerque e Paiva (2015). 
outro colorido ao falar de um crime de pistolagem ocorrido em Tabatinga.

De repente, no meio da tarde, a Cidade para! A polícia Federal bloqueia a Fronteira. Carros e pessoas suspeitas são revistados. 0 motivo estava perto dali: um agente federal peruano e o informante dele foram executados a tiros na porta de um hotel. 0 agente peruano trabalhava em parceria com a polícia federal brasileira que investiga a maior quadrilha de traficantes nessa tríplice fronteira, entre Brasil, Colômbia e Peru. No mesmo dia, os agentes chegaram ao suspeito do assassinato. Tabatinga vive um novo ciclo de violência. 0 governo colombiano reforçou o policiamento em Letícia por causa das FARC. Com a segurança ostensiva, os traficantes fazem o acerto de contas das quadrilhas em território brasileiro. (Cristina Serra).

Em seguida, a repórter entrevista uma jornalista que afirma ser comum, na Cidade, assassinatos como os retratos pela reportagem. A matéria continua com a repórter relatando a rotina de assassinatos que aterroriza a população e questionando uma moradora sobre "o que ela acha dessa situação de violência na cidade". Filmada e com o microfone em sua direção, a moradora balança a cabeça e não responde a repórter. Segue a reportagem explorando outra questão clássica da tríplice fronteira amazônica, qual seja a sua vastidão e dificuldade de controle efetivo do crime e da violência mobilizada pelo narcotráfico. Ao retratar uma abordagem da Polícia Federal a uma embarcação, a repórter fala de que a intenção da força policial brasileira é enfrentar o "tráfico formiguinha" cuja característica é o transito de pequenas quantidades de drogas "camufladas das mais diversas formas". Essa ideia é bastante comum, sobretudo, para policiais, pesquisadores e moradores que afirmam que o transporte de boa parte da cocaína produzida na tríplice fronteira é feito em pequenas quantidades, envolvendo pessoas que tem um contato eventual e efêmero com o tráfico de drogas. Voltarei a essa questão no tópico seguinte. 
A matéria da Globo continua com policiais federais encontrando um quilo de pasta base na bolsa de uma mulher filmada sendo algemada e presa. Para coroar a reportagem, a repórter entrevista Mário Sposito, delegado da Polícia Federal e reconhecido como um dos expoentes no "combate" as drogas na tríplice fronteira. Segundo ele,

Se nós tivermos outras alternativas de subsistência para essa população, veja não vamos acabar com o tráfico de drogas, exato, mas nós vamos minimizar esse quadro e vamos oferecer aqueles que não tem outra alternativa solução para sair do problema. Nós temos que ter o Estado presente, ter o Estado controlando para nos termos o conhecimento do que está ocorrendo nesse continente que é a Amazônia. (Mario Sposito).

Menos do que uma leitura do problema social da droga, a fala de Sposito trabalha com uma ideia bastante difundida sobre as relações entre moradores e tráfico de drogas em Tabatinga. Essa ideia se refere ao fato de que existem traficantes que movem esse mercado e, em virtude de problemas econômicos, qualquer pessoa que vive no trapézio amazônico, em tese, é um potencial trabalhador do narcotráfico. A reportagem é bastante abrangente e as ideias trabalhadas nesse material da Globo são replicadas em dezenas de outras reportagens. Tabatinga aparece de maneira recorrente como local de passagem para as drogas entrarem no Brasil, sendo afetada por esse trânsito e por relações que são mediadas pelo poder do narcotráfico. Assim, como demonstra uma reportagem da Revista Veja, os crimes de pistolagem são sempre um elemento presente em representações de uma "Cidade sem lei", em que a polícia, embora presente, não consegue executar um controle efetivo devido a multiplicidade de caminhos e envolvidos com o narcotráfico na região.

Em Tabatinga, até o que está dentro da lei apresenta riscos para o País. Às 21h19 da quarta-feira, 25 de maio, 80 estiva- 
dores descarregavam 15.000 sacos de cimento no principal porto da cidade. Tudo veio do Peru. A carga estava com toda a documentação em dia, garantiu Daniela Sampaio, única inspetora da Receita Federal em Tabatinga. O problema é que, no momento em que descarregavam o gigantesco carregamento, não havia qualquer fiscal. "Se fosse cocaína, por exemplo, nós estaríamos descarregando do mesmo jeito, mas sem saber", disse Geraldo Daniel Vela, presidente do Sindicato dos Estivadores de Tabatinga. As fronteiras do norte retratam um Brasil esquecido. (ABBUD, 2011).

A ideia de uma terra sem controle é fortemente alimentada pela imprensa nacional, criando uma representação exaustiva de perigo eminente a cada momento. Isso repercute em formas de falar da violência ao expor causalidades e protagonistas do crime como demonstra a matéria da Veja. Segundo a reportagem, as maiores plantações de drogas estão do outro lado do Rio Solimões, no Peru. São dessas terras que vem os israelitas. Eles são peruanos que pertencem a Associação Evangélica da Missão Israelita do Novo Pacto Universal e aparecem na matéria citados como "o principal grupo de produtores de folha de coca no Peru". Novamente, Mario Sposito é a referência para que a reportagem explique com riqueza de detalhes o que acontece na tríplice fronteira amazônica. "O contrabando desenfreado" é apontado por Abbud (2011) como elemento estruturante da violência, sendo ressaltada a presença de pistoleiros que atuam conscientes da incapacidade de um aparato efetivo de controle da violência pelo Estado brasileiro.

Em linhas gerais, as matérias nacionais são constituintes de uma Tabatinga imaginada, mas que vivencia problemas reais, em grande medida, redimensionados pelo discurso de quem olha para ela unicamente pelo prisma da violência mobilizada pelo narcotráfico. Como destaca Rondelli (1998, p. 146), o excesso de tematização da violência na cobertura jornalística brasileira "teve o efeito de constituir um determinado imaginário sobre a violência, que passou a informar e a produzir atitudes sociais a ela referenciadas". A violência não foi inventada pela imprensa, 
mas os acontecimentos narrados por ela contribuem para estruturar certas ficções controladas, em que o real ganha dimensões extraordinárias e sensacionais em virtude, entre outras coisas, da incidência constante de informações selecionadas de maneira unidimensional. Dificilmente, algum brasileiro conhecerá pela imprensa nacional uma Tabatinga diferente da retratada pela Globo e a Veja. As relações internacionais entre os três países, na visão da imprensa brasileira, também são reduzidas a instrumentalidade do controle policial das drogas, restando praticamente nenhum outro assunto que não seja o combate ao tráfico transfronteiriço. Assim, é possível falar a respeito das margens do Estado nação brasileiro pela violência, situando a fronteira como lugar perigoso e que deve ser controlado. Interessa agora saber o que as pessoas de Tabatinga têm a dizer sobre isso.

\section{"Aqui a bala tem nome e endereço certo"}

Posso estar equivocado, mas, como observado ao longo do trabalho de campo, Tabatinga é uma cidade tranquila para seus moradores e visitantes. Transitei por suas ruas, inclusive durante a madrugada, sem grande alvoroço ou temor. Não existem pessoas visivelmente circulando armadas por Tabatinga, muito menos um tráfico "escancarado" de drogas. Nunca fui surpreendido por ninguém me oferecendo drogas, por outro lado, em mais de uma ocasião me ofereceram mulheres. Apesar da aparente tranquilidade, uma caminhada Avenida da Amizade (principal via da Cidade e que a liga a Letícia) desperta a atenção pela quantidade de forças policiais e serviços públicos distribuídos pela sua extensão. É possível observar viaturas da Polícia Militar, Força Nacional e um ônibus da Estratégia Estadual de Segurança Pública Integrada para a Região de Fronteira e Divisas do Amazonas (ESFRON-AM) equipado com modernos dispositivos de monitoramento.

Todo o aparato de segurança, no entanto, não parece capaz de produzir e sustentar a ideia de uma cidade segura. Existe uma 
contradição muito peculiar na fala do morador de Tabatinga. Eles acreditam que vivem em um lugar tranquilo para os que estão fora do mundo crime, ou seja, os que não se envolvem com traficantes. Então, a tranquilidade não é resultado das forças de segurança que atuam no local, mas do seu comportamento em relação aos perigos e ameaça que realmente existem em Tabatinga. Assim, viver em Tabatinga pode ser realmente tranquilo, inclusive porque as pessoas acreditam que na tríplice fronteira "a bala tem nome e endereço certo". Segundo os moradores da cidade, ninguém morre por acaso na tríplice fronteira amazônica e as balas podem ser lidas como instrumentos portadores de identidade.

Ei má, foi uma forma humorística assim, quando dar-se essa frase aqui, os daqui mesmo fala assim: rapaz é tipo assim, aqui... como é o nome? Aqui tem nome da bala e tem endereço.

Aqui não tem bala perdida! E isso pode até acontecer em uma, em um milhão de chances. Aqui as balas são tudo endereçadas, entendeu? 0 cara não morre de graça. Dificilmente o cara morre de graça. Pode até ter, mas é uma em um milhão. (Grupo Focal com Estudantes da UFAM).

Para os moradores de Tabatinga "só morre quem tem que morrer" na tríplice fronteira amazônica. Os crimes são explicados como parte de envolvimentos com o tráfico de drogas, contrabando ou agiotagem. Em todos os casos eles se dão por acertos de contas entre pessoas envolvidas, em geral, com o tráfico de drogas. Existem também crimes passionais e narrativas de crimes políticos. 0 tráfico, no entanto, tem um peso maior nas explicações sobre a pistolagem em Tabatinga. Em suma, o morto nunca é alguém de bem que estava tranquilamente passeando pela rua e foi assassinado por acidente. A competência dos pistoleiros é ressaltada como elemento constituinte do crime na tríplice fronteira, sendo possível "viver em paz" desde que a pessoa não se envolva com o crime ou cumpra os compromissos assumidos. Este é um dado importante porque em Tabatinga é 
possível viver do crime desde que a pessoa seja honesta em suas negociações. Para morrer, inclusive, os moradores ressaltam que é preciso "vacilar muito", pois em Tabatinga os traficantes são compreendidos como pessoas que não matam por acaso ou sem a certeza de que foram trapaceados. Portanto, "querer enganar um traficante é como assinar a sentença de morte".

Como ocorre em outras cidades do País, a morte em Tabatinga ocorre preferencialmente entre envolvidos com o narcotráfico, sendo a imagem de competência dos pistoleiros um elemento importante para pensar como o sistema de acerto de contas funciona sem prejuízos para uma população que, em linhas gerais, "se acostumou a ver corpo estendido no chão". Eles são interpretados como consequência de um processo maior, em que o tráfico de drogas aparece como elemento constituinte de relações sociais na tríplice fronteira. Conforme destaca Aponte Motta (2012), entre meados dos anos de 1970 e finais dos anos de 1980, a bonanza produzida pelo narcotráfico de cocaína produziu mudanças importantes na dinâmica da tríplice fronteira, com uma urbanização acelerada e novas possibilidades econômicas decorrentes do comércio de cocaína. Olivar (2013) ressalta que esse é um tempo do qual "as pessoas falam com saudades". Segundo ele, foi a época de grandes bordeis, em que era possível achar dólares nas ruas, com um fluxo intenso de pessoas vindas de todas as partes da Colômbia para Letícia em busca da promessa de riqueza. Essa é a época também do surgimento do Cartel de Letícia, liderado por Evaristo Porras ${ }^{23}$, que, na década de 1980, foi um dos mais importantes da Colômbia (Steiman, 2002). A atuação desse Cartel teve um papel importante na trí-

${ }^{23}$ A história de Evaristo Porras foi destaque na imprensa colombiana em março de 2010 quando os jornais ressaltaram sua morte na miséria. A ascensão e o fim deste importante traficante colombiano ilustra situações exemplares do que foi esse movimento de bonanza e depressão do tráfico de drogas na tríplice fronteira amazônica. Cf. "Evaristo Porras, el triste final de un capo", na Revista Cromos. Disponível em http://www.cromos. com.co/personajes/reportaje/articulo-evaristo-porras-el-triste-final-de-un-capo. Acesso $18 / 09 / 2015$. 
plice fronteira tanto em seu auge, quanto em seu desmantelamento em virtude do que movimentou e o que ficou após o seu fim. Evaristo Porras fez fortuna e uma carreira política em Letícia, tornando-se um dos importantes fornecedores de coca do famoso Cartel de Medelín de Pablo Escobar. É possível encontrar em Letícia prédios que ficaram do tempo áureo da cocaína e da atuação do Cartel de Letícia. Sua existência e prosperidade são elementos importantes do imaginário construído pelo tráfico de drogas na tríplice fronteira amazônica.

Conforme evidenciam Balieiro e Nascimento (2015), o tráfico de drogas atua como um dos dinamizadores econômicos da região nos anos 2000, mesmo sem a pungência econômica da bonan$z a$. Hoje em dia, a leitura geral é que não existem mais "grandes traficantes" 24 do porte de um Evaristo Porras ou Pablo Escobar. Embora as forças policiais destaquem a existência de grandes movimentações de drogas por quadrilhas organizadas, há na tríplice fronteira esquemas de tráfico que privilegiam o segredo, a discrição e as saídas que possibilitem o transporte e consumo dos recursos do narcotráfico sem chamar atenção para quem vive desse mercado ilícito. Muitas pessoas, inclusive, participam do tráfico de drogas eventualmente, recebendo pagamentos circunscritos a um trabalho pontual cujo fim do recurso adquirido pode ser a reforma da casa, a compra de uma passagem, a abertura do próprio negócio, o financiamento de uma moto ou até de uma campanha política, entre outros interesses ocasionais. O que não é possível, em contatos contínuos ou circunstanciais com traficantes, é tentar "passar a perna", enganar outros envolvidos com o crime, tentando ficar com o seu dinheiro em detrimento da efetivação de seu compromisso.

Funciona assim [crimes de pistolagem] Você compra uma droga, ai tipo assim, você compra fiado. Aí, de repente você

${ }^{24}$ Convém esclarecer que essa é uma ideia relativa, proveniente da percepção de interlocutores que tem certa visão do problema em relação a imagens mais fortes de traficantes renomados e com fama internacional. 
some com a droga ou porque a polícia prende ou porque tu quer enganar o cara. Aí, eles chamam e dizem "ou você paga a minha droga, ou você morre". E é assim que funciona, se você não pagar, você morre. Você pode fugir, mas nunca mais voltar para cá, porque no dia que você voltar pode ter passado 10 anos quando aconteceu isso, a pessoa acha que esqueceu, mas não esquece. Quando você bota os pés aqui, geralmente, eles já tão sabendo que você vai chegar, já tem um pistoleiro te esperando. Ai matam mesmo! Aí, é assim! (Polícia Civil entrevistado).

Uma pessoa que compra a droga ou fica responsável por determinada quantidade de droga para transporte ou movimentação dos mercados ilegais transfronteiriços assume um compromisso no qual "sua vida está empenhada”. Há entendimento de que não existe outra forma de os traficantes cobrarem suas dívidas que não seja matando quem lhe deve. Isso não acontece automaticamente. Escutei relatos a respeito de traficantes que dão prazo e costumam usar datas como o final do ano para cobrar a dívida. Também ouvi de moradores relatos de traficantes que deixam o devedor viver, em casos que ele afirma que a droga foi interceptada pela polícia ou piratas que atuam no Rio Solimões ${ }^{25}$. Esses casos podem garantir ao devedor certa liberdade. Contudo, os traficantes irão acompanhar o caso, seguir a pessoa e quando perceberem que ela está os enganado então irão matá-la. Os assassinatos, em geral, acontecem em lugar público. Durante a investigação encontrei dificuldade para saber quem são essas pessoas que matam e morrem, pois, como já discutido, o perfil dos envolvidos no narcotráfico na região parece ser bastante abrangente.

Não existe biotipo rígido para isso [participar do tráfico]. Você vai acabar detendo, prendendo, pessoas jovens, de certa idade, pessoas com formação, com educação

${ }^{25}$ Os casos de pirataria no Rio Solimões compõem um capítulo a parte e estão incluídos em um vasto acervo de questões a serem enfrentadas mais adiante. 
universitária, formados, administrador, advogados, como já foi um caso aqui. Você vai prender brasileiro, peruano, russo, colombiano, espanhol. Então não existe um biotipo. Pessoas com feições bonitas, pessoas com feições feias, mulheres sedutoras, senhoras de idade, não existe, não existe! Fugindo um pouco dessa região, por exemplo, Santa Catarina, fez uma prisão recente, recente faz no máximo quatro meses que eu digo, de uma mula que estava levando determinada quantidade de droga de Florianópolis para a Austrália. Era uma mulher, praticamente uma modelo de feição. Era uma profissional digamos de entretenimento masculino, né, mas uma pessoa de feições lindas. E o tráfico se utiliza desses subterfúgios, porque infelizmente a população brasileira é preconceituosa. Por isso que eu digo, o tráfico não possui um biotipo fixo, não possui uma regra fixa. Então na verdade o que nós temos é: não existe perfil para mula, não existe, não existe. (Policial Federal entrevistado).

Este é um dos relatos mais interessante e com o qual ainda tento aprender, pois não parece possível encontrar um circuito fechado, um movimento específico ou as pessoas que compõem o mundo do crime na fronteira. 0 "envolvido" com o tráfico de drogas pode ser "qualquer um". Isto torna o controle desse tipo de crime na fronteira extremamente difícil. Não poucas vezes o morto pode surpreender as pessoas na cidade porque "ninguém esperava". Ao falar da violência os moradores situam a droga como um componente que está presente em praticamente todos os homicídios, salvo aqueles que são ações passionais. Quando uma "pessoa de bem" morre, por exemplo, é possível que a comunidade fique assustada, mas logo séries de coisas passam a fazer sentido e detalhes do envolvimento da mesma com o tráfico vão surgindo. Em casos assim, as falas da violência cuidam em explicar os encadeamentos entre a pessoa e o crime, demonstrando como o tráfico de drogas atrai e seduz mesmo os que parecem não está ao seu alcance.

Em suma, encontrei diversos relatos em que a cocaína aparece como um componente importante da vida social na tríplice fronteira, mobilizando múltiplos sujeitos para sua produção, trans- 
porte, circulação e distribuição da droga para as demais cidades brasileiras. Ela compõe um sistema que ao longo da fronteira agencia pessoas e cria relações que atendem determinados fins, mas não estão fixadas e muito menos são imóveis. Há um movimento que segue um fluxo de negociações e conflitos que compõem a fronteira e o imaginário em torno dos caminhos seguidos pela cocaína através, sobretudo, dos rios do Amazonas. Ao falar sobre isso, os moradores de Tabatinga revelam avaliações distintas das que a imprensa e mesmo as instâncias de segurança fazem do tráfico na região. 0 que preocupa a população de Tabatinga não me parece ser a droga que passa, mas a que fica nas cidades do Alto Solimões e tem produzido efeitos práticos na vida de quem mora na região.

\section{"O problema é a droga que fica"}

Os moradores falam da violência em Tabatinga como um problema que tem se intensificado, principalmente as práticas de vitimização de moradores em função de assaltos e furtos. Eles relatam também que o uso drogas aparece cada vez mais associado a problemas de violência doméstica, homicídio e suicídio em tribos indígenas que vivem no Alto Solimões. Existe um sistema interno de narcotráfico e consumo de drogas cujas demandas locais passam a estruturar acertos de contas e problemas vividos pela circulação da cocaína na região. Essas situações revelam um intricado mundo de problemas decorrentes da multiplicidade de envolvimentos e contradições presentes em acontecimentos interculturais e transnacionais. Para os moradores, a violência é um problema que envolve as nações e os trânsitos entre populações que gozam de status sociais diferenciados na região.

Nas falas da violência, os peruanos aparecem como principais protagonistas da violência em Tabatinga. O Estado brasileiro é recorrentemente acusado de ser promiscuo em sua política de 
controle social das migrações decorrentes do Peru. Assim, peruanos que traficam cocaína são apontados como pessoas que levam vantagens econômicas na tríplice fronteira. Segundo meus interlocutores, os peruanos encontram meios de lavar o dinheiro em Tabatinga, adquirindo comércios legais e tornando-se bem sucedidos empresários em território brasileiro. As supostas facilidades experimentadas por peruanos acusados por brasileiros de tráfico de drogas integram processos sistemáticos de sujeição criminal $^{26}$ e estigmatização dessa população. Entre outras coisas, ela é acusada por brasileiros de ser protagonista dos crimes de tráfico e assaltos na cidade de Tabatinga.

Pode descer aí no porto e vê que os comércios é tudo de peruano. Agora porque? Porque eles ganham dinheiro com o narcotráfico, arruma um casamento com uma brasileira e depois pronto... 0 cara vem pra cá, com dinheiro do tráfico e sai comparando casa, comercio. Não tem nenhum controle. Aí muitos deles atravessam a fronteira e ainda vem roubar aqui! (Comerciante de Tabatinga entrevistado).

Comerciantes peruanos são apontados como suspeitos de comandar o narcotráfico hoje em Tabatinga. A aparente facilidade com que os peruanos entram, abrem negócios e se casam no Brasil é apresentada como umas das principais preocupações de brasileiros que falam do Estado nacional como uma entidade incapaz de manter controle social ou mesmo favorecer a apropriação indevida de seu território. "Rapaz aqui a culpa é tudo daquela Placa ali”, diz um vereador fazendo referência a expressão "Brasil, um país de todos" presente em uma placa na fronteira do Brasil com a Colômbia. Portanto, para o mesmo vereador, a situação pode ser definida da seguinte forma: "aqui, o cara vem

\footnotetext{
${ }^{26}$ Sobre o conceito de sujeição criminal como parte integral de um processo mais amplo de construção social do crime ver MISSE, Michel. Sobre a construção social do crime no Brasil. Acusados e acusadores: estudos sobre ofensas, acusações e incriminações. Rio de Janeiro: Revan, 2008.
} 
do Peru, dá um pombada e já é brasileiro”. Ao questionar se os colombianos também não gozavam das mesmas facilidades, o vereador se referiu a eles como povo irmão em virtude de gozar de um cenário social parecido com o Brasil. Não obstante, a entrada de produtos colombianos em Tabatinga é narrada com ressentimento em virtude dos brasileiros, em geral, não poderem comercializar "absolutamente nada em território colombiano". A qualidade do controle de fronteira realizado pelo governo colombiano é citada como uma referência em meio às narrativas relacionadas à ineficácia do controle brasileiro.

Como é possível observar, as falas da violência criam sujeitos e estabelecem relações de aproximação e distanciamento que integram o cotidiano de Tabatinga. Cotidiano que ouso pensar, como Machado Pais (2003), no entremeio de rotinas e rupturas. Elas compõem as múltiplas facetas dos repertórios de quem fala da cidade a luz de situações de violência que a compõem como realidade, também, imaginada. São nos encontros entre essas múltiplas populações que as diferenças e diferenciações compõem formas de distinguir uns e outros em uma comunidade política na margem de um Estado nacional que busca se fazer presente, mas não pode ser interpretado, pura e simplesmente, como uma estrutura que acomoda as multiplicidades existentes na fronteira.

As dinâmicas entre fronteiras também refletem múltiplas relações entre sujeitos que são classificados de maneira diferenciada nas falas da violência. Além dos peruanos, os povos indígenas, em geral, também são incluídos em um campo semântico de preconceitos construídos em torno da ideia de que essas populações colaboram sistematicamente com o narcotráfico. As populações tradicionais são apontadas como potencialmente perigosas em virtude de seus conhecimentos da floresta e seus caminhos. A situação econômica delas é ressaltada para afirmar sua vulnerabilidade diante de traficantes com boas propostas financeiras. "O cabra dali sem dinheiro, chega um oferecendo para 
ele levar uma coisinha, ele vai mesmo", ressalta um barqueiro ao se referir ao trabalho de pescadores de comunidades ribeirinhas seduzidos por traficantes.

As falas da violência criam lugares, cenários e sujeitos que são acusados de protagonizarem e sofrerem em virtude de crimes variados, mas que tem o narcotráfico como uma força estruturante do imaginário transfronteiriço. Seria possível continuar ainda esse caminho, explorando como as drogas criam outros problemas relacionados às relações conjugais e com os filhos em ambiente doméstico. Em linhas gerais, o narcotráfico é um componente importante das falas de violência, sendo associado a problemas diversos. Compreender suas dinâmicas e efeitos simbólicos é um desafio em aberto, assim como uma melhor reflexão sobre situações que não parecem encontrar acomodação nos repertórios explorados nesse texto. Os casos de violência contra a mulher são exemplos de situações que ainda merecem melhor atenção e nos colocam diante de desafios analíticos a serem explorados futuramente. As vivências da violência nas comunidades tradicionais e os conflitos oriundos das lutas pelos recursos naturais da Amazônia também são elementos ainda a serem pensados com mais atenção.

\section{Considerações Finais}

Conforme observei no trabalho de campo, os moradores de Tabatinga acreditam que a cidade não é violenta, afinal, “aqui, a bala tem nome e endereço certo". Para os moradores, só morre quem tem que morrer. 0 maior problema da cidade, em relação à violência, não é a droga que passa, mas "a droga que fica", os traficantes que circulam, as pessoas que enriquecem e utilizam o dinheiro do tráfico para interferir nas relações comerciais na Cidade. Entre brasileiros, peruanos, colombianos e indígenas as interações envolvem uma economia moral do reconhecimento baseada na participação de cada um desses grupos sociais nas 
tramas do crime e da violência na tríplice fronteira. 0 manejo dessa economia moral nas falas da violência é uma das questões importantes que ilustram a reflexão do trabalho.

Os moradores oferecem um vasto acervo de julgamentos morais que compõem seu dia a dia e sua avaliação a respeito das origens dos problemas de violência na cidade. Para começar, as relações entre brasileiros, colombianos e peruanos são retratadas como desiguais. Para os interlocutores da pesquisa, os peruanos são os principais responsáveis pela criminalidade local, sendo atribuído a eles protagonismo tanto na produção de drogas quanto nas ocorrências de crimes contra o patrimônio em Tabatinga. Ao procurar saber a causa desse fenômeno, os moradores explicaram que a culpa, em certa medida, é do governo brasileiro. Segundo um dos interlocutores, "essa história de 'Brasil um país de todos' lascou a gente porque eles chegam aqui e acham que podem fazer tudo". Embora a visão dos colombianos seja menos desfavorável do que a dos peruanos, eles também são apontados como protagonistas de ilegalidades, entre elas, o contrabando de mercadorias que não poderiam ser vendidas no Brasil (ALBUQUERQUE e PAIVA, 2015). A ideia de o "Brasil, ser um país de todos", na visão dos interlocutores, é apontada como causa para "estrangeiros" se sentirem livres para "fazer e acontecer", enquanto os brasileiros são submetidos à responsabilização e controle mais eficientes.

Falar da violência foi um meio de os brasileiros falarem de "seu" Estado-nação. Em linhas gerais, o Estado aparece nas falas como objeto de lutas simbólicas e políticas (BOURDIEU, 2014). As reflexões dos interlocutores buscam explicar os sentidos que estruturam o Estado na fronteira, ao mesmo tempo em que problematizam politicamente suas ações em suas mais diversas instâncias de atuação. Embora exista uma presença ostensiva de forças policiais na cidade de Tabatinga (Polícia Militar, Polícia Civil, Polícia Especial de Fronteiras, Força Nacional de Segurança), a segurança pública é um problema grave, sendo comum escutar 
relatos de roubos de motos, assaltos a residências e crimes de pistolagem. 0 contraponto à situação de Tabatinga para seus moradores é a cidade de Letícia, na Colômbia. "Enquanto aqui você pinta e borda, lá por qualquer coisinha você é preso", relatam os moradores. É comum observar as forças policiais nas cidades, mas as dinâmicas da atuação sempre são retratadas como completamente diferentes. Em andanças pelas fronteiras é possível observar que, no Brasil, os policiais estão sempre em viaturas e, grosso modo, atuam em abordagens específicas de busca e apreensão de drogas e armas. Em Letícia, na Colômbia, é comum a polícia estar na fronteira entre as duas cidades e realizar alguma abordagem. Na circulação pela cidade colombiana é comum ver os policiais a pé, como também agentes das forças armadas em pontos estratégicos realizando um serviço de guarda.

As determinações do que é possível fazer ou não nas duas cidades é uma questão bastante interessante em relação a como os moradores pretendem se comportar em uma e outra nação. As permissões e proibições da vida entre fronteiras são questões práticas para pessoas que vivem nos limites de territórios nacionais. Nas práticas cotidianas dos moradores de Tabatinga, questões que envolvem o monopólio da violência física (WEBER, 1999) passam por suas necessidades e desejos de maior controle do território brasileiro. Isso, no entanto, não é suficiente porque eles também falam da necessidade e desejo de maior controle de "quem é brasileiro". Definir a nacionalidade é uma questão que aparece em relatos que classificam outros povos e nações pelos problemas vividos em uma fronteira localizada na maior floresta tropical do mundo. Considerar as formas de classificação que o Estado brasileiro aplica aos estrangeiros permitiu observar na prática os problemas apontados por Bourdieu (20014) em suas reflexões sobre o monopólio da violência simbólica e os atos de consagração de quem, em tese, age em nome do interesse nacional. Nas vivências transfronteiriças o que é interesse nacional é sempre um problema que envolve conflitos muito específicos das relações entre pessoas de diferentes nações. 


\section{Ref erências Bibliográficas}

ALBUQUERQUE, José Lindomar. Conflito e integração nas fronteiras dos "brasiguaios". Caderno CRH, v. 23, n. 60, p. 579-590, 2010.

ALBUQUERQUE, José Lindomar; PAIVA, Luiz Fábio Silva. Entre nações e legislações: algumas práticas de "legalidade" e "ilegalidade" na tríplice fronteira amazônica (Brasil, Colômbia, Peru). Revista Ambivalências, v. 3, n. 5, p. 115-148, 2015.

ABBUD, Bruno. As desprotegidas portas do Brasil. Revista Veja. São Paulo: Editora Abril, 2011. Disponível em http://veja.abril.com.br/noticia/brasil/as-desprotegidas-portas-do-brasil. Acesso em 20/09/2015.

BALIEIRO, Luiz Felipe de V. NASCIMENTO, Izaura Rodrigues. Tríplice Fronteira Brasil, Peru e Colômbia e as implicações com o narcotráfico. Textos \& Debates. Boa Vista, n. 26, p. 85-98, 2015.

BARREIRA, César. Cotidiano despedaçado: cenas de uma violência difusa. Coleção Conflitos Sociais e Práticas Políticas. Campinas: Pontes, 2008.

BOURDIEU, Pierre. Sobre o Estado. São Paulo: Companhia das Letras, 2014.

COSTA, Sérgio. Dois Atlânticos: teoria social, anti-racismo, cosmopolitismo. Belo Horizonte: Editora UFMG, 2006.

DAS, Veena; POOLE, Deborah. El estado y sus márgenes: etnografias comparadas. Cuadernos de antropología social, n. 27, p. 19-52, 2008.

DAS, Veena. Sujetos del dolor agentes de dignidad. ORTEGA, Francisco A. (org.). Bogotá: Universidade Nacional de Colombia, 2008.

DAS, Veena. Fronteiras, violência e o trabalho do tempo: alguns temas wittgensteinianos. Revista brasileira de ciências sociais, v. 14, n. 40, p. 31-42, 1999.

EUZÉBIO, Emerson Flávio. Fronteira e horizontalidade na Amazônia: as cidades gêmeas de Tabatinga (Brasil) e Letícia (Colômbia). ACTA Geográfica. Boa Vista, v. 8, n. 18, pp. 1-19, set./dez. de 2014.

FOUCAULT, Michel. Em defesa da sociedade. São Paulo: Martins Fontes, 1999. O nascimento da biopolítica. São Paulo: Martins Fontes, 2008.

FREITAS, Geovani Jacó de. Ecos da violência: narrativas e relações de poder no Nordeste canavieiro. Rio de janeiro: Relume Dumará, 2003.

MISSE, Michel. Sobre a construção social do crime no Brasil. Acusados e acusadores: estudos sobre ofensas, acusações e incriminações. Rio de Janeiro: Revan, 2008. 
MOTTA, Jorge Aponte. Comercio y ocio em la transformación del espacio urbano fronteirizo de Leticia y Tabatinga. Espacios urbanos y sociedades transfronteirizas en la Amazonia. Leticia: Universidade Nacional de Colombia, 2012.

OBSERVATÓRIO DA VIOLÊNCIA DE GÊNERO NO AMAZONAS. Mapa da violência contra mulheres na mesorregião amazônica do Alto Solimões-AM. Benjamin Constant, AM: Universidade Federal do Amazonas, 2013.

OLIVAR, José Miguel N. Mercados do sexo em territórios transfronteiriços: gênero e circulações na fronteira Brasil-Colômbia. Relatório de pesquisa. Campinas: Fundação de Amparo à Pesquisa do Estado de São Paulo (FAPESP) e Núcleo de Estudos de Gênero (PAGU) da Universidade Estadual de Campinas, 2013.

OLIVAR, José Miguel N., CUNHA, Flávia Melo da., ROSA, Patrícia Carvalho. Presenças e mobilidades transfronteiriças entre Brasil, Peru e Colômbia: o caso da "migração peruana na Amazônia brasileira". Tomo. №. 26. Universidade Federal de Sergipe: jan/jun, 2015.

PAIS, José Machado. Vida cotidiana: enigmas e revelações. São Paulo: Cortez, 2003.

RAMÍREZ, Socorro. A Colômbia e o Brasil, separados (e unidos) pelo comércio e pela segurança. Revista Nueva Sociedad. Buenos Aires, n. 9, pp. 90-107, 2009.

RONDELLI, Elizabeth. Imagens da violência: práticas discursivas. Tempo Social. São Paulo, v. 10, n. 2, p. 145-157, 1998.

WEBER, Max. Economia e sociedade: fundamentos da sociologia compreensiva. V. 1. Brasília: UnB, 1999.

ZALUAR, Alba. Integração perversa: pobreza e tráfico de drogas. Rio de Janeiro: FGV Editora, 2004.

Recebido em 26/12/2015

Aprovado em 30/12/2015 
